\title{
Editorial
}

\section{Anatomic repair of double discordant hearts}

The management of patients with congenital heart defects, associated with atrioventricular discordance continues to remain a challenge for paediatric cardiac surgeons and cardiologists. The paper by Acar and colleagues in this issue ${ }^{1}$ is a timely review of their institution's management programmes for this condition, and highlights the role of the tricuspid valve in determining the outcome in this group of patients. They note in their paper, as have others, ${ }^{2-4}$ the relatively high morbidity and mortality associated with the classic repair of congenitally corrected transposition, when the right ventricle remains in the systemic circulation. Hence, the move to consider other approaches, in particular, the double switch repair where the left ventricle is relocated to the systemic circulation.

Acar et al had a study population of 62 patients from a total population of 141 , and in analysing this group of patients they note that the prevalence of tricuspid regurgitation in the preoperative group was significantly higher in patients who had an associated ventricular septal defect (91\%). However, tricuspid regurgitation was also common in patients with an intact ventricular septum $(38 \%)$, and those with a ventricular septal defect and some form of pulmonary obstruction (36\%). The surgical mortality for conventional surgery, where the right ventricle remains in the systemic circulation, was five of 15 patients, and the mortality for the double switch type of repair was one of nine patients.

Our own experience ${ }^{5}$ from November 1991 to August 1997 comprises 13 patients having undergone a RastelliSenning type of repair, 16 patients an atrial-arterial switch repair, and three a Senning repair together with tunnelling of the ventricular septal defect to the systemic ventricle. Two of the 16 patients with the atrial-arterial switch repair had undergone training of the left ventricle by pulmonary artery band, and there are three additional patients who have undergone pulmonary artery banding to prepare the left ventricle awaiting surgery. Thus there are a total of 35 patients in this series aged from 6 months to 40 years (median 2.5 years) with weights of $5.3 \mathrm{~kg}$ to $60 \mathrm{~kg}$ (median $13.3 \mathrm{~kg}$ ). Of note, tricuspid valve regurgitation was significant in 14 of the 16 patients undergoing atrial-arterial switch but in only one patient undergoing the RastelliSenning procedure. In the 16 patients undergoing the atrial-arterial switch procedure the ventricles were always on the opposite side to the vena cava. This was also the case for the 13 patients undergoing the Rastelli-Senning procedure except for one case where the ventricles were on the same side of the vena cava and this had implications for placement of the valve conduit from the right ventricle to the pulmonary arteries.

There has been one hospital death in the RastelliSenning group and one late death after two years in a patient who had undergone an atrial-arterial switch procedure from biventricular failure. Over the same time, two other patients came forward for a Rastelli-Senning procedure but this could not be performed: in one patient because of total anomalous pulmonary venous drainage and in the other because the ventricular septal defect was strictly inlet and could not be committed to the aorta. The latter patient died following a conventional repair some nine months after surgery following development of severe tricuspid regurgitation and right ventricular dysfunction.

Many centres have now documented the problems of classic repair for congenitally corrected transposition, and the paper by Acar et al also emphasises the high mortality and morbidity associated with the classic repair. We agree with Acar and colleagues' conclusions that patients who have tricuspid valve abnormalities require careful management in terms of volume loading of the heart to try and prevent the development of tricuspid valve regurgitation. If this does develop then further tricuspid annular dilatation and progressive dilatation of the right ventricle will create a vicious circle leading to worsening tricuspid regurgitation and heart failure. If tricuspid regurgitation does develop, pulmonary artery banding may in itself reduce or stop the development of tricuspid valve regurgitation as well as possibly training the left ventricle for the double switch type repair. We certainly agree that restoring the right ventricle to the subpulmonary position is a more efficient way of achieving tricuspid valve competence than any direct attempt to repair the tricuspid valve.

We also agree that the more complex double switch procedure is indicated when patients have right ventricular failure with or without tricuspid regurgitation. It is also indicated when right ventricular dysfunction with or without tricuspid regurgitation follows the classic repair, as long as the morphological left ventricle can be trained by pulmonary artery banding. When atrioventricular discordance is associated with pulmonary stenosis or atresia and this is causing significant cyanosis, the ventricular septal defect can be tunnelled to the aorta with a valve conduit placed from the right ventricle to the pulmonary artery - the Rastelli-Senning procedure. In a minority of cases (three in our series) the Senning procedure together with the intraventricular tunnelling to relocate the left ventricle to the aorta is sufficient without the need for a valved conduit.

At this time, we suggest that patients who have well balanced systemic and pulmonary circulations without any noticeable desaturation, usually in association with a ventricular septal defect and moderate pulmonary valve stenosis, are best managed conservatively without surgical intervention. When they do become symptomatic either by virtue of cyanosis or the development of tricuspid regurgitation we suggest that an anatomic repair would be the best option.

The longer term follow up of these patients is unknown. The conduit change in the Rastelli-Senning group might be difficult as the conduit is usually behind the sternum, and changing it might provide technical difficulties. There are also concerns about the long term rhythm problems associated with the Senning and Mustard procedure. In our series we have one patient who underwent the atrial-arterial switch procedure who has required urgent aortic valve replacement because of progressive neoaortic valve regurgitation. Most of our patients who have had an atrial-arterial switch also have a degree of neoaortic valve regurgitation. Whether this will become progressive is worrying and certainly they will require careful monitoring.

It seems that in the short term the double switch repair for patients with atrioventricular discordance is the proce- 
dure of choice, in patients where operative intervention is indicated. However, much longer term follow up is necessary before we can be sure that complications relating to conduit change, rhythm disturbances, and neoaortic valve regurgitation will become a major problem.

O STUMPER

W J BRAWN

Birmingham Children's Hospital NHS Trust, Steelhouse Lane, Birmingham B4 6NH, UK
1 Acar P, Sidi D, Bonnet D, et al. Maintaining tricuspid valve competence in double discordance: a challenge for the paediatric cardiologist. Heart double discorda

2 Huhta JC, Danielson GK, Ritter DG, et al. Survival in atrio-ventricular discordance. Paediatr Cardiol 1985;6:57-60.

3 Sano T, Riesenfeld T, Karl TR, et al. Intermediate term outcome after intracardiac repair of associated cardiac defects in patients with atrio-ventricula and ventriculoarterial discordance. Circulation 1995;92(suppl 2):272-8.

4 Termignon JL, Leca F, Vouhe PR, et al. "Classic" repair of congenitally corrected transposition and ventricular septal defect. Ann Thorac Surg 1996;62:199-206.

5 Reddington AN, Brawn WJ, Deanfield JE, et al, eds. The right heart in congenital heart disease. London: Greenwich Medical Media Ltd, 1998.

\section{Delayed appearance of coronary aneurysms in Kawasaki disease}

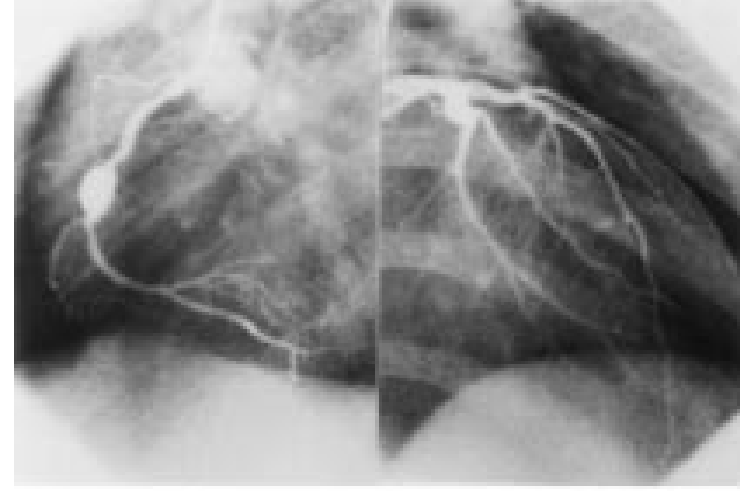

5 years 7 months

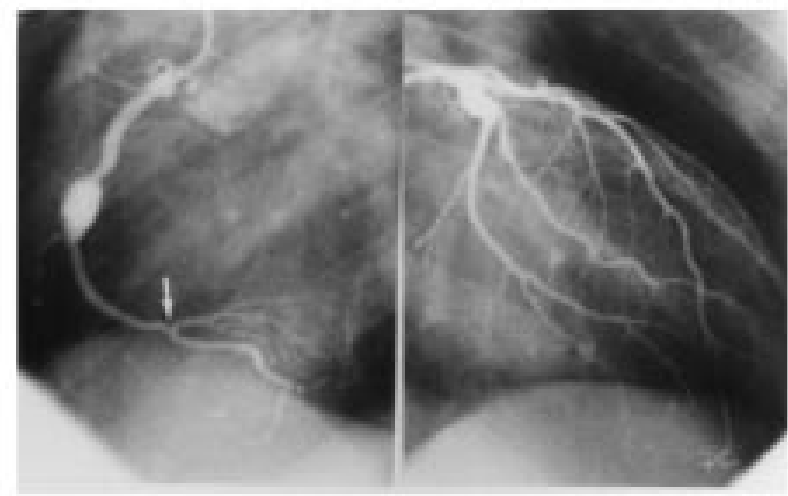

8 years 3 months

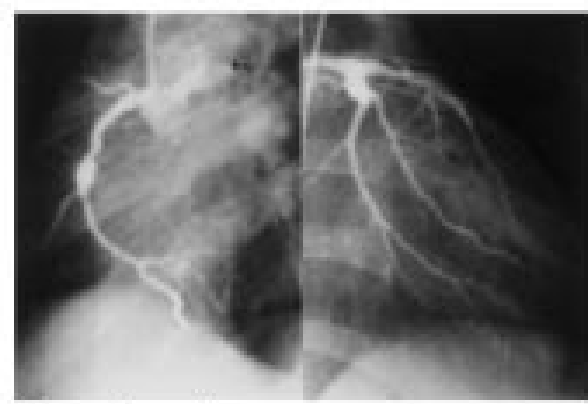

12 vears 4 months

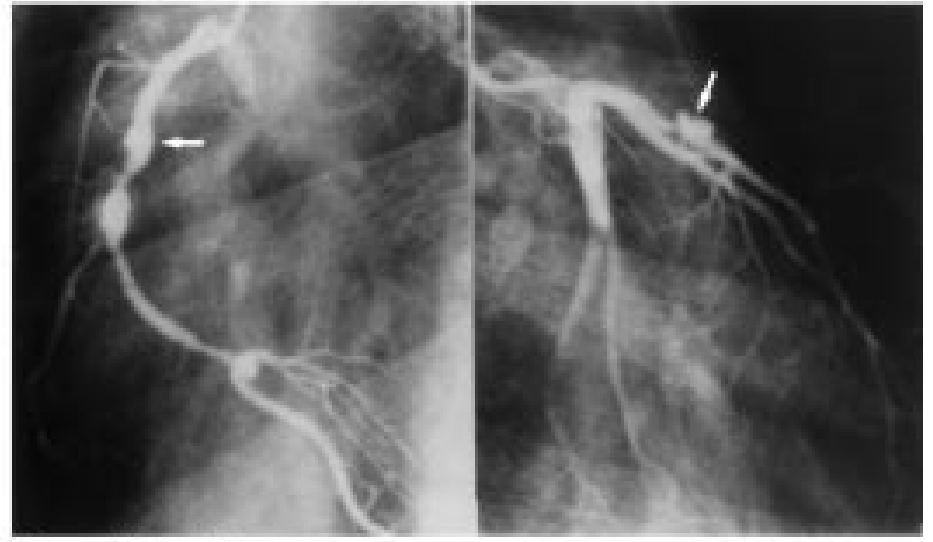

16 years 10 months
A boy aged 16 years and 10 months had typical Kawasaki disease diagnosed when aged 1 year and 8 months. Selective coronary angiography at the age of 5 years and 7 months showed a giant aneurysm (diameter $8.6 \mathrm{~mm}$ ) on the right coronary artery (segment 2), and dilatation of the left circumflex artery (segment 11 ; diameter $7 \mathrm{~mm}$ ). Although coronary angiography at age 8 years 3 months showed similar dilated lesions at segments 2 and 11, a new small dilated lesion with a diameter of $2.7 \mathrm{~mm}$ appeared at segment 4 (arrow). The dilated lesions at segments 2 and 11 were smaller at age 12 years and 4 months, and calcifi- cation was apparent in the aneurysm at segment 2 . Two new aneurysms were observed at age 16 years and 10 months, one in the left anterior descending artery (segment 6 ), and the other in the right coronary artery proximal to the formerly existing aneurysm (arrow). Mild localised stenosis was detected at the proximal and distal ends of the aneurysm in segment 2 . The aneurysm in segment 4 increased to a diameter of $4 \mathrm{~mm}$.

HIDESHI TOMITA SHIGETO FUSE SHUNZO CHIBA 